\title{
Effect of cessation of creatine supplementation on endogenous creatine synthesis
}

\author{
X. $\mathrm{Li}^{1}$, M. Xiang ${ }^{2}$, L. S. Harbige ${ }^{2,3}$ and H. $\mathrm{Ai}^{1}$ \\ ${ }^{1}$ Division of Nutrition and Biochemistry, Institute of Sports Medicine, The Third Hospital, Peking University, Beijing, \\ People's Republic of China, ${ }^{2}$ Centre for Biosciences Research, School of Science, University of Greenwich, Kent ME4 4TB, \\ UK and ${ }^{3}$ Medway School of Pharmacy, University of Kent and University of Greenwich, Kent ME4 4TB, UK
}

Creatine (Cre) can be obtained exogenously from either the diet or supplementation ${ }^{(1-3)}$. It can also be endogenously synthesised in man and other mammals ${ }^{(4,5)}$. One of the adverse effects of Cre supplementation is that L-arginine:glycine amidinotransferase (L-AGAT), a key enzyme in the endogenous Cre synthesis in mammals, may be severely inhibited ${ }^{(6)}$. The present study investigated the time-course of recovery of L-AGAT activity and guanidinoacetic acid (GAA) concentration after 1 week of supplementation with $3.0 \mathrm{~g}$ Cre/kg body weight per d Cre in adult male Sprague-Dawley rats. On days 1, 2, 4, 8, 16 and 32 (ten treatment and ten control rats per time point) after the $7 \mathrm{~d}$ supplementation period L-AGAT activity and GAA concentration in the kidney recovered (\%) by 32.8, 51.5, 76.1, 94.4, 100.2 and 102.0 (Figure (A)) and 77.9, 86.2, 96.8, 100.6, 101.1 and 108.0 (Figure (B)) respectively when compared with their respective controls. The total Cre in the gastrocnemius muscle decreased rapidly and reached its lowest level on day 4 after the supplementation period, and then increased gradually. No significant differences were found in serum Cre kinase activity and serum creatinine in the experimental groups when compared with their respective control groups.

These findings indicate that in rats the reduction in L-AGAT activity and GAA concentration associated with supplementation with $3.0 \mathrm{~g}$ $\mathrm{Cre} / \mathrm{kg}$ per $\mathrm{d}$ for 1 week could be reversed, suggesting that short-term and high-dose Cre supplementation does not result in depression of endogenous Cre metabolism. As little is known about the effect of Cre supplementation on the immune system, investigation of the effect of long-term and high-dose Cre supplementation on endogenous Cre metabolism in the immune cells of rats will be of interest.
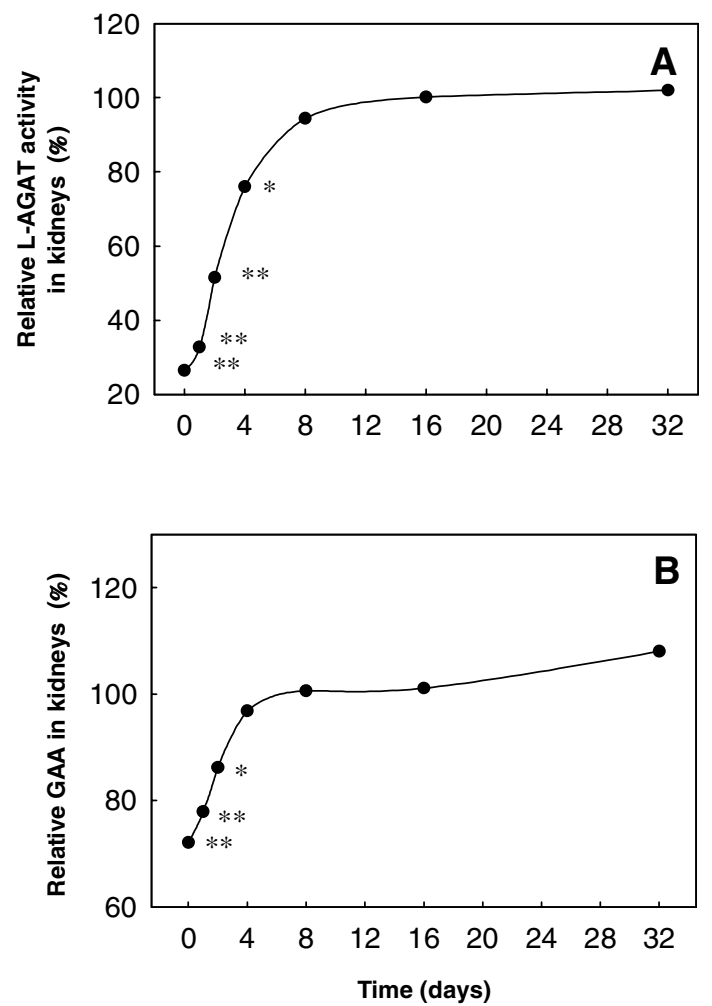

1. Pan JW \& Takahashi K (2007) Am J Physiol 292, R1745-R1750

2. Candow DG \& Chilibeck PD (2007) J Nutr Health Aging 11, 185-188.

3. Silva AJ, Machado Reis V, Guidetti L, Bessone Alves F, Mota P, Freitas J \& Baldari C (2007) J Sports Med Phys Fitness 47, 58-64.

4. Derave W, Marescau B, Vanden Eede E, Eijnde BO, De Deyn PP \& Hespel P (2004) J Appl Physiol 97, 852-857.

5. Braissant O, Henry H, Loup M, Eilers B \& Bachmann C (2001) Brain Res Mol Brain Res 86, $193-201$.

6. Wyss M \& Kaddurah-Daouk R (2000) Physiol Rev 80, 1107-1213. 